\title{
La mala escritura: síntoma de un mundo académico problemático
}

DOI: https://doi.org/10.32870/dse.v0i11.279

\section{Cristina Palomar Verea*}

Reseña del libro

Aprenda a escribir mal. Cómo triunfar en las Ciencias Sociales, de Michael Billig México: Cambridge University Press, Editorial del Colegio de Posgraduados, La Gaya Ciencia y Fundación Colegio de Posgraduados en Ciencias Agrícolas, A.C., 2014

Es frecuente, entre los académicos que participan en la formación de nuevos investigadores, la preocupación por la mala calidad de la escritura de la gran mayoría de sus alumnos y las especulaciones que hacen en torno a cuáles serán las razones de tal problema que se muestra en todas sus caras: mala ortografía y redacción, pero también desconocimiento de la gramática y falta de pensamiento lógico y de vocabulario suficiente para expresar correctamente las ideas. Aunque también el lenguaje oral está plagado de algunos problemas de pronunciación, de muletillas y de frases hechas que se ponen de moda y no dicen nada, parece que este lenguaje es menos problemático que la escritura, la cual además muestra la tendencia a echar mano de expresiones y formas de construcción lo más distantes posible de las usadas en la vida diaria, lo cual implica, por una parte, una cantidad de palabras mayor que las estrictamente necesarias para expresar la idea en juego, y por otra, el recurso exagerado de un vocabulario especializado o selecto articulado en complejas oraciones gramaticales. Hay que decir sin embargo que éste no es solamente un rasgo del lenguaje en los alumnos: muchos profesores e investigadores comparten esa tendencia y de esa manera estimulan su uso y afianzamiento.

Al parecer, la curiosidad en torno a lo que puede explicar la mala escritura en el ámbito académico de la educación superior fue lo que condujo a Michael Billig a escribir el libro titulado Aprenda a escribir mal. Cómo triunfar en las Ciencias Sociales, en donde el autor se lamenta de la mala escritura que suele encontrarse entre los académicos que trabajan en el campo de las ciencias sociales, la cual muestra el abuso de la jerga académica en la misma proporción que parece consi-

* Psicoanalista y doctora en ciencias sociales con especialidad en antropología social. Profesora investigadora titular en el Departamento de Estudios en Educación de la Universidad de Guadalajara. Investigadora nacional nivel II. Correo electrónico: crispalvertina@hotmail.com 
derarse a la claridad como un defecto de los legos. El libro se inscribe en una línea de trabajo crítico del lenguaje utilizado por los académicos; de hecho Billig menciona a Blanschard (1954), quien afirmaba que escribir sin claridad era muestra de "malos modales", y hace referencia al escándalo desatado por Andreski (1971) cuando enjuició a los científicos sociales por su incapacidad para escribir con claridad. Igualmente, el autor menciona también el escándalo promovido por Sokal (2010), quien fustigó a los teóricos posmodernos por escribir deliberadamente de manera oscura.

El punto de vista de Billig es el de un insider: habla desde adentro del campo de las ciencias sociales; él mismo es un científico social y ha sido profesor universitario por cerca de 40 años. Estudió filosofía y psicología en la Universidad de Bristol, y desde 1985 es profesor de ciencias sociales en la Loughborough University y miembro del influyente Discourse and Rhetoric Group.

El libro comienza con una introducción en la que se exponen las experiencias e hipótesis que llevaron a Billig a escribir el libro, así como una breve exposición del contenido general de éste. Aparecen después siete capítulos en donde el autor desarrolla su argumento y presenta suficientes evidencias para sostenerlo, seguidos de conclusiones y recomendaciones, de numerosas referencias y concluye con un índice onomástico.

El autor da en su libro abundantes muestras de que conoce bien el estilo que suele utilizarse en las ciencias sociales, en la filosofía y en la psicología. Aunque menciona los estilos de diversos académicos — desde Freud a Derrida, Lacan y Deleuze, hasta Talcott Parsons, Robert Merton y Robert Linton-, el foco de su crítica en este libro no es el estilo con el que escriben, sino las condiciones bajo las cuales están trabajando en el mundo actual los científicos sociales académicos, así como la naturaleza lingüística de lo que éstos producen como escritores de las ciencias sociales, ya que Billig considera que hay un vínculo directo entre ambas cuestiones. Es decir: la escritura de los académicos obedece sobre todo a problemas estructurales del campo en el que se desempeñan profesionalmente y refleja en su forma dichos problemas. En este sentido sigue de cerca algunas de las ideas de Bourdieu sobre el mundo académico y sus determinaciones estructurales, y da cuenta de cómo es posible hacer un análisis amplio de dicho ámbito a partir de uno de sus graves síntomas contemporáneos: la mala escritura.

El autor explora en su libro la naturaleza de la escritura académica y desmenuza algunos de los aspectos que la caracterizan, para sostener su premisa de base: que la mala escritura académica no es producto de una "mala educación" sino que, por el contrario, es el resultado de una especie de "exceso" de cultura académica. Su argumento central tiene dos partes: la primera sostiene que el trabajo de los académicos se desarrolla en una cultura cada vez más comercial, dado que en la actualidad las universidades, las disciplinas y los individuos son llevados a competir económicamente. La expectativa es que los académicos publiquen continua y abundantemente, lo cual ocasiona que cada vez se produzcan más trabajos escritos apresuradamente y que los circuitos de circulación para éstos sean cada vez más cerrados. La segunda parte es la afirmación de que en el núcleo de dicha cultura se han puesto el éxito y la vanidad, lo cual se filtra en el contenido de los 
escritos académicos: "cuando escribimos estamos presumiendo constantemente de nuestros enfoques, nuestros conceptos, nuestras teorías, nuestra manera de hacer ciencias sociales y lo que estos productos pueden lograr" (p. 16).

A partir de su experiencia en la docencia, Billig afirma que el joven estudiante, además de hacer lo necesario para convertirse en un profesional de la rama elegida en las ciencias sociales, también busca asociarse a un enfoque específico, una perspectiva teórica o un cuerpo de trabajo ya existente. Para lograrlo, un elemento fundamental es la terminología técnica del ámbito elegido, su aceptación y asimilación, así como la consideración de que esa terminología es superior al lenguaje ordinario. El autor cita estudios de científicos sociales sobre la vida universitaria, su cultura comercial y las formas en que los postgraduados se convierten en académicos profesionales, y recurre a distintos ejemplos. Lo más interesante es el señalamiento de que el abuso de la jerga académica y de los grandes conceptos impacta en el contenido mismo de lo que se escribe, al dar de esa manera menos información sobre las acciones humanas que cuando se utiliza un lenguaje claro y sencillo.

Billig hace una muy documentada exposición de las características de la vida académica contemporánea, las transformaciones de las universidades, la fragmentación de las disciplinas, la masificación de la educación superior con la consecuente investigación producida en masa que requiere, a su vez, de una profusa publicación de textos de calidad dudosa. Más adelante, para sostener su tesis de que la mala escritura es resultado de mucha educación, toma el caso de la sociología de Pierre Bourdieu para hablar del "lenguaje pomposo" y de cómo éste tiene efectos tanto en los profesores como en los alumnos. Argumenta que la utilización de dicho lenguaje se relaciona con el proceso de la producción de la propia identidad como académico adaptado a todos los planos del ámbito profesional y como signo de pertenencia a una comunidad que lo legitima y recompensa.

Luego Billig explica en qué consiste la discusión que se da en torno a las virtudes o problemas de la utilización de la jerga académica, ya que considera que es muy fácil descalificar su argumento contra la mala escritura en ciencias sociales considerándolo solamente como un alegato contra la jerga mencionada. Para mostrar que no se trata de eso, analiza cómo la mala escritura, además de abusar de dicha jerga, tiene otros rasgos, como el abuso de los nombres y los acrónimos, la mala utilización de los verbos y la producción de una terminología inherentemente ambigua. También discute los argumentos que Bourdieu produjo contra el lenguaje ordinario, para luego señalar que las tendencias en la vida académica contemporánea han conducido a un riesgoso acercamiento entre las formas gramaticales del mundo comercial y el académico, lo cual sería conveniente revertir.

En otra parte, el autor habla de algunos vicios de la mala escritura de los científicos sociales como la necesidad de regodearse en sus escritos de los tipos de cosas teóricas que crean, particularmente las que terminan con "ización" o "ificación", que parecen tomarse como señales de distinción y de una posición superior a quienes usan palabras cortas. Pero sobre todo explica la tendencia de estos académicos a convertir a las personas en cosas por medio de ciertos mecanismos como 
ensamblar la teoría y los conceptos con escasas referencias a gente real y a sus vidas, lo cual deriva en una escritura imprecisa. Billig recurre a la escritura de Freud - una doble escritura - para exponer sus argumentos, pero habla también de la escritura de otros científicos.

El autor considera que es mejor usar verbos ordinarios que conceptos rimbombantes e imprecisos. Establece la diferencia entre la gramática y la ideología, abunda en el problema de la nominalización y reflexiona sobre la importancia de distinguir las cosas de los procesos al escribir sobre cada uno. También afirma que la voz pasiva es la más utilizada en la escritura científica, con lo cual los académicos logran "eliminar de la escena a los actores humanos, permitiendo a las cosas ficticias seleccionadas ser las estrellas del espectáculo" (p. 167). El autor se concentra en el campo de la sociología para afirmar que los académicos de dicho campo, mediante su uso de los nombres, crean retóricamente "cosas sociológicas" cuya existencia sostienen. Recurre como ejemplos de ese uso a la "gubernamentalidad", la "cosmopolitización" y el "análisis conversacional", para luego profundizar más aún en los efectos de la nominalización en el campo de la psicología social.

El libro está muy bien escrito y ampliamente documentado; tiene un estilo ágil y claro, además de un agudo sentido del humor. La traducción al español y el cuidado de la edición tienen algunos problemas, pero aun así puede decirse que publicar este libro es un gran acierto, ya que pone en perspectiva el problema concreto de la escritura para dar muchas pistas para pensar lo que está sucediendo en la educación superior de nuestros días. Una de las principales conclusiones del libro es que deberíamos hacer un esfuerzo por escribir de formas más claras y simples; para cerrar, Billig propone cautelosamente seis sugerencias para "escribir mal", es decir, para promover una escritura clara y sencilla que se aleje las perniciosas tendencias en la escritura de los científicos sociales de nuestros tiempos.

Al terminar de leer el libro uno se pregunta si ese mundo al que el autor hace referencia refleja también lo que sucede en México con los jóvenes académicos de ciencias sociales. Finalmente su experiencia es la de un profesor en un país del primer mundo con un sistema educativo mucho más viejo, consolidado y firme que el nuestro. La reflexión que surge a partir de esa pregunta parte del reconocimiento de que es algo indudable que en nuestro país también enfrentamos un enorme problema de mala escritura en los alumnos en el nivel de la educación superior pero que, sin embargo, en nuestro medio este problema no tiene que ver solamente con un exceso de educación. En nuestro país hay otros planos problemáticos involucrados en la mala calidad de la lectoescritura, y aunque sin duda también es cierto que nuestras universidades reflejan ya parte de las tendencias globales que definen la educación superior y la investigación científica de maneras similares a lo que Billig describe en relación con el mundo académico inglés, en el encuentro de esas tendencias globales con nuestras circunstancias locales se producen efectos específicos que habría que analizar con cuidado para lograr una explicación más clara acerca de lo que en nuestro caso provoca, con una combinación particular de factores, el mismo grave problema: la mala escritura de los académicos en ciencias sociales. 